\title{
THE CARBOHYDRATE MOIETY OF THE ACTIVATOR PROTEIN FOR GLUCOSYLCERAMIDE $\beta$-GLUCOSIDASE
}

\author{
Akira Sano and Norman S. Radin \\ Mental Health Research Institute, University of Michigan, Ann Arbor, Michigan 48109
}

Received July 5, 1988

SAP-2 is a family of heat-stable, acidic glycoproteins which stimulate enzymatic hydrolysis of glucosylceramide. We studied the carbohydrate moieties of a ConA-binding form of SAP-2. The protein contained glucosamine, galactose, mannose, and fucose; galactosamine and sialic acid were not detectable. Sodium dodecyl sulfate-polyacrylamide gel electrophoresis and silver staining showed three bands of $6.5,8.5$, and $10 \mathrm{kDa}$. After deglycosylation with peptide $\mathrm{N}$-glycosidase, SAP-2 eluted more slowly from the $\mathrm{C}_{4}$ column and showed a single band of $4 \mathrm{kDa}$. From carbohydrate analysis it was evident that deglycosylation had removed more than $90 \%$ of the sugars. These data indicate that SAP-2 possesses N-linked complex or hybrid type oligosaccharide chains. The specific activity of the deglycosylated protein in the glucosidase stimulation assay was unaffected. $\odot 1988$ Academic Press, Inc.

The glycosphingolipid, glucosylceramide, is catabolized by a $\beta$-glucosidase (E.C.3.2.1.45) in a wide variety of organisms and cells to form ceramide and glucose. The enzyme activity in vitro is greatly stimulated by taurocholate, acidic lipids, or - in the presence of a small amount of acidic lipid - by an activator protein that has been called Factor P (1), HSF (2), SAP-2 (3), coglucosidase (4), cohydrolase sphingolipid 1 (5), AP (6) and sphingolipid activator protein A (7). For brevity here we call it SAP-2. The protein has been isolated from bovine and human spleen and from human brain $(4,5,8,9)$. It showed heterogeneity in PAGE and concanavalin A chromatography yielded binding and nonbinding forms of the protein $(5,6)$. The bands separated by PAGE were found to have similar stimulating activities, stainability on PAGE with Stains All, and immunoreactivity with polyclonal antibodies prepared against the mixture (5). SAP-2 accumulates greatly in the spleen of patients with Gaucher disease (genetic defect in glucosidase activity) and its accumulation in liver could be induced by injecting emulsified glucosylceramide into mice (10). SAP-2 apparently acts by combining with the enzyme and acidic lipid to form an activated complex, rather than by solubilizing the substrate (11). The electrophoretic evidence of heterogeneity could be attributed to substitutive modifications, such as glycosylation. Evidence for the latter explanation came from the concanavalin A experiments $(5,6)$ but it was not known whether carbohydrate is needed for activity.

Recently we isolated a ConA-binding form of SAP-2 and determined its amino acid sequence. ${ }^{1}$ In the present study we describe the carbohydrate moieties of the protein and their effect on the protein's ability to activate the frglucosidase.

Abbreviations: SAP-2, activator protein for glucocerebroside glucosidase; SDS, sodium dodecyl sulfate; PAGE, polyacrylamide gel electrophoresis; glucosylceramide, glucosylceramide or glucocerebroside; Buffer A, $10 \mathrm{mM}$ Na phosphate, $\mathrm{pH} 7.0,0.02 \% \mathrm{NaN}_{3} ; \mathrm{HPLC}$, high performance liquid chromatography.

${ }^{1}$ A. Sano and N.S. Radin, unpublished work. 


\section{MATERIALS AND METHODS}

Materials - Hartley guinea pigs were decapitated and the livers were frozen rapidly on dry ice, then stored at $-80^{\circ} \mathrm{C}$ before use. Commercially available frozen guinea pig livers from Pel-Freez Biologicals were also used. DEAE-Sephacel and Sephadex G-75 (fine) were from Pharmacia; crystalline BSA, Grade A, was from Calbiochem; acetonitrile, HPLC grade, was from Fisher Scientific; trifluoroacetic acid HPLC/Spectro grade was from Pierce Chemical; triethylamine $99 \%$ pure was from Aldrich Chemical; peptide N-glycosidase from Flavobacterium meningosepticum (glycopeptidase $F$ mixed with endoglycosidase F) was from Boehringer Mannheim, Cat. No. 878740; other materials were from Sigma Chemical.

The isolation procedure of SAP-2 has been described separately. ${ }^{1}$ Commercially available guinea pig livers were extracted and the SAP-2 was purified by ammonium sulfate precipitation, DEAE-Sephacel ion exchange, Sephadex G-75 size exclusion, and ConA-Sepharose. The forms binding to this last column were fractionated further by reverse phase chromatography with a $\mathrm{C}_{4}$ column and a major fraction was collected for study.

SAP-2 Assay-Samples were assayed for stimulatory activity toward a partially purified preparation of glucosidase by incubation with methylumbelliferyl glucoside in acetate buffer, $\mathrm{pH} 4.5$, with Triton $\mathrm{X}-100$ as previously described (12).

Protein Determination and Amino Acid and Carbohydrate Analyses-The bicinchoninic acid method (13) was used for protein measurement with BSA as standard. Amino acid analyses were done with phenylisothiocyanate derivatization by Linda L. Johnson at the University of Michigan Protein Sequencing Facility by the methods of Tarr (14). Carbohydrate composition was determined by Dr. Fulvio Perini at the Department of Pharmacology with a modified version of the $o$-phthalaldehyde method of Perini and Peters (15), using a Kratos amino acid analyzer equipped with an FS 950 fluorometer and a cation exchange column (AA511, Interaction Inc.). Sialic acid was measured by a fluorimetric assay (16).

Deglycosylation-90 $\mu \mathrm{g}$ of SAP-2 were treated with 8-12.5 Boehringer Mannheim units of protein Nglycosidase $\mathrm{F}$ in $200 \mu \mathrm{l}$ of $0.25 \mathrm{M}$ Na phosphate, $50 \mathrm{mM}$ EDTA, $10 \mathrm{mM}$ o-phenanthroline, $\mathrm{pH} 9.3$, at $37^{\circ} \mathrm{C}$. After $5 \mathrm{~h}$ a second portion of enzyme was added to the incubation mixture. Portions of the solution were taken at the indicated times and acidified with TFA. Following centrifugation at 13,000 $\times g$ for $1 \mathrm{~min}$ the supernatant fluid was subjected to HPLC with a $\mathrm{C}_{4}$ column to remove the enzyme and salts. An incubation $\mathrm{pH}$ of 9.3, rather than the optimal $\mathrm{pH}$ of 8.5 , was used in order to eliminate interference by endo- $\beta-\mathrm{N}$ acetylglucosaminidase $F$ in the enzyme preparation (17).

Electrophoresis-SDS-PAGE on a $20 \%$ gel with $4.5 \%$ stacking gel, using a discontinuous buffer, was carried out with the Pharmacia Phast System. The samples were reduced prior to electrophoresis by heating $5 \mathrm{~min}$ with SDS and mercaptoethanol according to the Pharmacia instructions. Gels were stained with silver by the method of Heukeshoven and Dernick (18) with a slight modification according to Pharmacia.

\section{RESULTS}

Carbohydrate analysis showed that the protein contained similar amounts of glucosamine and mannose, and lesser amounts of galactose and fucose (Table I). The total amount was $11 \%$ of the protein weight. Fewer than $3 \mathrm{nmol} / \mathrm{mg}$ protein of galactosamine and sialic acid were seen. These observations are qualitatively similar to those of Peters et al. (8), who analyzed a mixture of SAP-2's from human Gaucher spleen. However they reported finding sialic acid too. Kleinschmidt et al. (19) isolated a similar protein, which activated

Table 1

Carbohydrate content of SAP-2 before and after treatment with peptide $\mathrm{N}$-glycosidase $\mathrm{F}$

\begin{tabular}{lcc}
\hline & \multicolumn{2}{c}{$n$ mollmg protein } \\
\cline { 2 - 3 } & Native & Deglycosylated \\
\hline Glucosamine & 250 & 23 \\
Galactose & 145 & 12 \\
Mannose & 205 & 18 \\
Fucose & 40 & $<3$ \\
\hline
\end{tabular}


sphingomyelinase and was called $\mathrm{A}_{1 \mathrm{a}}$. They reported glucose as the major component (45\% of the protein), together with small amounts of acetylglucosamine, mannose, and galactose.

SDS-PAGE of our preparation revealed three bands of $6.5,8.5$, and $10 \mathrm{kDa}$, visible with silver staining (Fig. 1). The bands were of similar darkness and width. In our previous study of ConA-binding SAP-2 from human spleen, we saw just two bands in native gels with Stains All (5).

A time course study of the HPLC elution patterns, following peptide N-glycosidase treatment, showed diminution of the original peak and the appearance after $5 \mathrm{~h}$ of three new (but overlapping) peaks. By $10 \mathrm{~h}$ (Fig. 2), the first two of the new peaks were a little larger while the slowest peak had grown even more and the original peak was now substantially absent. The new peaks eluted more slowly from the $C_{4}$ column than the original SAP-2, which is to be expected in view of the hydrophobic nature of the column packing and the increase in hydrophobicity that appears on removal of sugars. The elution pattern was not changed after another $5 \mathrm{~h}$ incubation with additional enzyme.

The deglycosylation treatment removed more than $90 \%$ of the sugars from SAP-2 (Table I), without appreciably changing the amino acid composition (Table II). The latter observation indicates that the o-phenanthroline included in the incubation mixture successfully blocked any protease present in the glycosidase preparation (20). The molar ratios of the sugars were little changed by the deglycosylation (Table I), suggesting that all forms of SAP-2 had reacted similarly. The SDS-PAGE showed a single band of $4 \mathrm{kDa}$ (Fig. 1), which indicates that all three bands had been glycosylated and were derived from a single peptide backbone.

Assay of the deglycosylated product showed that the specific activity was unchanged at $35 \mathrm{units} / \mu \mathrm{g}$ protein. Thus the carbohydrate side chain is unnecessary for activation of glucosylceramide glucosidase.

Some SAP-2 was also purified with the omission of the concanavalin A-binding step. Study of the pooled active fractions with SDS-PAGE showed the presence of several bands, the fastest corresponding to $4 \mathrm{kDa}$.

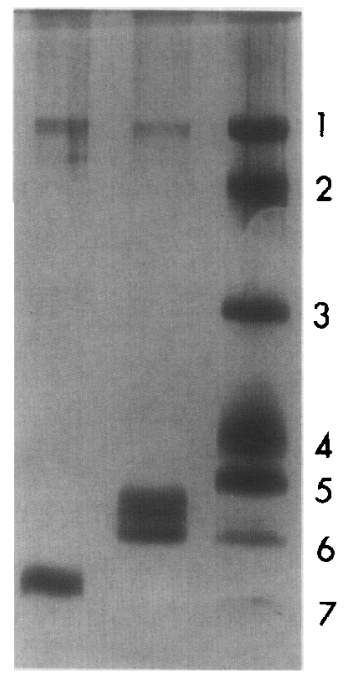

Fig 1. SDS PAGE gel of deglycosylated SAP-2, stained with silver. Right lane: standard proteins $(1=\mathrm{BSA}, 2=$ ovalbumin, $3=\alpha$-chymotrypsinogen, $4=$ myoglobin, $5=$ cytochrome $c, 6=$ aprotinin, $7=$ oxidized insulin $\beta$ chain). Center lane: $15 \mathrm{ng}$ of intact SAP-2; left lane: the equivalent amount of SAP-2 after $10 \mathrm{~h}$ of incubation with glycosidase. The slow-moving bands at the top, visible in the two left lanes, arose from contaminants in the mercaptoethanol and were seen in other lanes. 


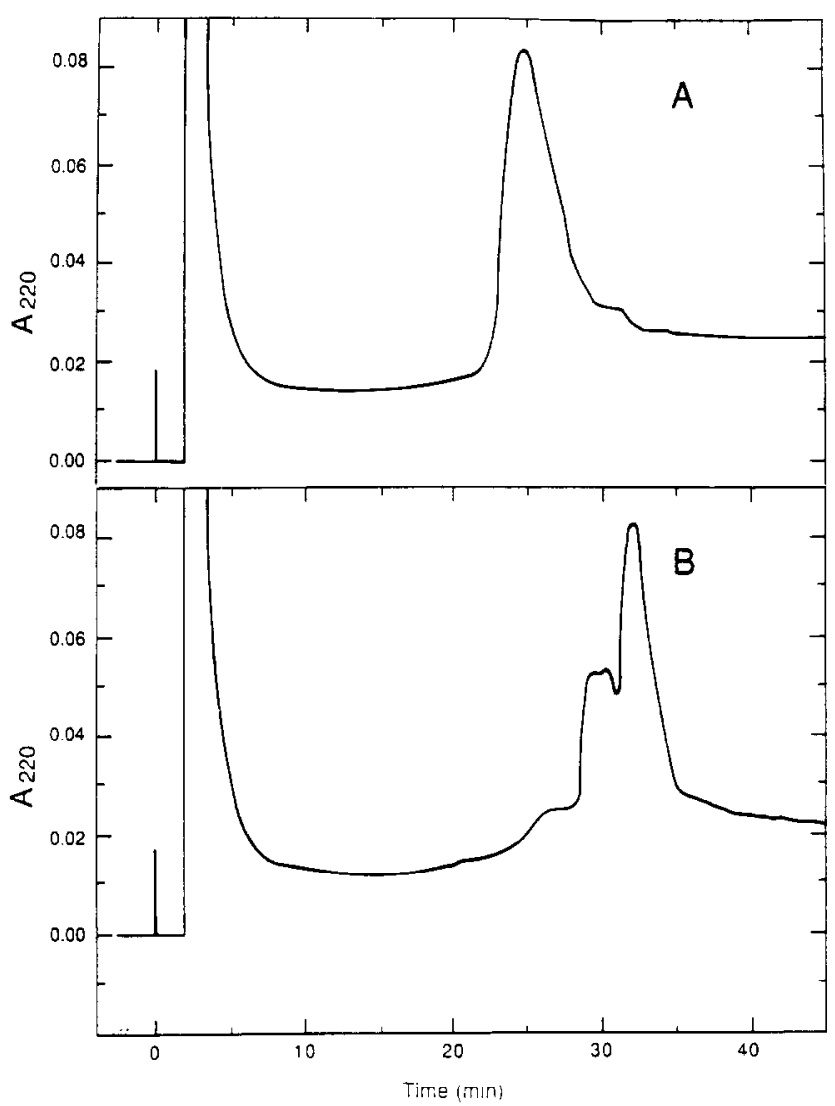

Fig 2. Reverse phase chromatography with $30 \mu \mathrm{g} \mathrm{SAP-2,} \mathrm{monitored} \mathrm{at} 220 \mathrm{~nm}$. Fig. 2A: zero-time control, SAP-2 and protein N-glycosidase F; Fig. 2B: SAP-2 and enzyme $10 \mathrm{~h}$. The control run without SAP-2 (not shown) yielded only the initial pass-through peak. Separation was accomplished with a high-porosity $\mathrm{C}_{4}$ reverse phase column (Alltech Macrosphere $300 \mathrm{C}_{4}, 4.6 \times 150 \mathrm{~mm}, 5 \mu \mathrm{m}$ particles), monitored at $220 \mathrm{~nm}$. The elution solvent was a linear gradient of $55-65 \%$ acetonitrile in $0.1 \%$ TFA. Other details have been described separately. 1

Only the $4 \mathrm{kDa}$ band was present after deglycosylation of this preparation, so it seems likely that some of the SAP-2 molecules are not glycosylated. The two SAP-2 preparations, isolated with and without the ConASepharose step, yielded very similar analytical data for total amino acid composition (data not shown).

\section{DISCUSSION}

One question about SAP-2 is whether the carbohydrate moieties are needed for the glucosidase stimulating activity. The enzyme is a highly hydrophobic protein that acts on a hydrophobic substrate, with the collaboration of a hydrophobic acid (such as phosphatidylserine), and it might possibly require a watersolubilizing cofactor in order to carry out the hydrolysis. Conceivably this explains the role of SAP-2. Our findings showed that reducing the hydrophilicity of SAP-2 by removing sugar moieties did not reduce its effectiveness as a stimulator. It therefore seems likely that the hydrolytic process takes place in a lipoidal environment. This conclusion is supported by the fact that the optimum $\mathrm{pH}$ for the reaction, about 4.5 , is close to the pI's of the two proteins, meaning that they are rather insoluble in water for that reason as well. 
Table 2

Amino acid composition of SAP-2

\begin{tabular}{lcc} 
& \multicolumn{2}{c}{ mol percent } \\
\cline { 2 - 3 } & Native & Deglycosylated \\
\hline Ala & 6.0 & 6.2 \\
Arg & 2.1 & 1.9 \\
Asp & 4.3 & 3.7 \\
1/2Cys & 5.8 & 5.5 \\
Glu & 13.4 & 11.1 \\
Gly & 4.0 & 4.4 \\
His & 1.3 & 1.6 \\
Ile & 4.3 & 4.5 \\
Leu & 14.5 & 15.1 \\
Lys & 5.4 & 5.4 \\
Met & 3.2 & 3.2 \\
Pro & 3.1 & 3.3 \\
Ser & 11.8 & 12.4 \\
Thr & 4.5 & 4.1 \\
Tyr & 2.5 & 2.7 \\
Val & 13.7 & 14.4 \\
\hline a Determined as cysteic acid & \\
\hline \multirow{2}{*}{ ar } & &
\end{tabular}

The notable microheterogeneity in the different forms of SAP-2 is clearly duc, in large part, to the variety of sugar substitutions on the peptide backbone. This is seen in the ability of glycosidase $\mathrm{F}$ to convert almost all forms to an apparently homogeneous peptide (the $4 \mathrm{kDa}$ band), the ability of a ConA-Sepharose column to separate the protein into three fractions, and the low molar content of fucose. However, there are additional sources of microheterogeneity, as shown by the three peaks seen after deglycosidation (Fig. 2) and the finding of some $\mathrm{N}$-terminal amino acid partial degradation. ${ }^{1}$ Microheterogeneity in the oligosaccharide side chains of lysosomal proteins may be a common characteristic $(21,22)$.

The changes in chromatographic elution pattern during glycosidase treatment could be interpreted to mean that the first two, barely separated peaks (Fig. 2) represented partially deglycosylated forms of SAP-2. However their failure to diminish in size, even on further incubation with fresh glycosidase, suggests that they differ from the main product (the slowest peak) by minor differences in the peptide backbone or by substitutions on the side chains.

The apparent molecular weights of the three bands, $6.5,8.5$, and $10 \mathrm{kDa}$, seen in SDS-PAGE of the unmodified SAP-2 preparation differ considerably from that of the deglycosylated material (4 kDa) and that calculated from amino acid sequencing (8743). ${ }^{1}$ The amount of sugar detected by analysis could not raise the observed mass of the $4 \mathrm{kDa}$ protein enough to account for the apparent values. It is likely that the sugars reduce the hydrophobicity of the protein enough to reduce the amount of bound SDS, thereby slowing electrophoretic migration. There is in addition a distinct influence of the net negative charge, seen with small proteins in SDS-PAGE (23), as well as the influence of the large proportion of hydrophobic amino acids in SAP-2 (Table 2).

Other laboratories, using SAP-2 preparations from other sources, have reported different results from SDS-PAGE. Fujibayashi et al. (3) found two or three bands of 9-10 kDa with human skin fibroblasts; in a later paper, immunolabeling experiments in vitro yielded very high values during the initial synthetic steps, 
followed by bands at 9 and $12 \mathrm{kDa}(24)$. Treatment with endoglycosidase $F$ resulted in a single reactive band of 7.6 kDa. Ranieri et al. (6) found 3 and 5-6.5 kDa for Gaucher spleen and Berent and Radin (4) found 6.2 $\mathrm{kDa}$ for bovine spleen. It seems likely that the different molecular weights are due, in part at least, to differences in SDS-PAGE technology; this is a problem with small acidic glycoproteins.

Studies of the subcellular localization of SAP-2 $(4,25)$ showed that it paralleled the distribution of glucosidase , a lysosomal enzyme. Additional evidence that SAP-2 is a lysosomal protein came from the observation that it is associated with the glucosylceramide storage deposits in lysosome-like particles of the Gaucher cell (25).

From the sugar compositional analysis and from the fact that SAP-2 contains a single sequence, Asn-XThr, to which the carbohydrate moiety is bound, ${ }^{1}$ it would appear that the oligosaccharide is either of the complex type or the hybrid type. The uptake of SAP-2 by cultured neuroblastoma cells was found to be blocked considerably by mannose-6-phosphate and a pentamannosyl phosphate (26), suggesting that SAP-2 contains a mannosyl phosphate group. This appears to be a requirement for incorporation of lysosomal enzymes into lysosomes, via the Man-6-P receptor (27). However, $\beta$-glucosidase does not have such a group (21) and its uptake into neuroblastoma cells was not blocked by mannose phosphate; its uptake was, however, aided by inclusion of SAP-2 plus phosphatidylserine (26). We suggest that its complex with SAP-2 and acidic lipid allows it to enter lysosomes by a "piggy-back" mechanism.

The report of a very high level of glucose in the Gaucher activator protein (19) supports the hypothesis that SAP-2 is a $\beta$-glucoside in one of its initial forms, and that $\beta$-glucosidase is needed for its further processing (28). This hypothesis explains why the SAP-2 of Gaucher spleen occurs at such a high concentration and why it migrates in PAGE as a larger, more diffuse mixture of forms (5).

ACKNOWLEDGMENT-- This study was supported by Grant NS 03192 from the National Institutes of Health. The author, NSR, is a recipient of the Senator Jacob Javits Neuroscience Investigator Award from the National Institutes of Health.

\section{REFERENCES}

1. Ho, M.W., and O'Brien, J.S. (1971) Proc. Natl. Acad. Sci. U.S.A. 68, 2810-2813.

2. Basu, A., Glew, R.H., Daniels, L.B., and Clark, L.S. (1984) J. Biol. Chem. 259, 1714-1719.

3. Fujibayashi, S., Kao, F., Jones, C., Morse, H., Law, M., and Wenger, D.A. (1985) Am. J. Hum. Genet. 37, 741-748.

4. Berent, S.L., and Radin, N.S. (1981) Arch. Biochem. Biophys. 208, 248-260.

5. Iyer, S.S., Berent, S.L., and Radin, N.S. (1983) Biochim. Biophys. Acta 748, 1-7.

6. Ranieri, E., Paton, B., and Poulos, A. (1986) Biochem. J. 233, 763-772.

7. Christomanou, H., Aignesberger, A., and Linke, R.P. (1986) Biol. Chem. Hoppe-Seyler 367, 879-890.

8. Peters, S.P., Coyle, P., Coffee, C.J., Glew, R.H., Kuhlenschmidt, M.S., Rosenfeld, L., and Lee, Y.C. (1977) J. Biol. Chem. 252, 563-573.

9. Wenger, D.A. and Roth, S. (1982) Biochem. Int. 5, 705-710.

10. Datta, S.C., and Radin, N.S. (1986) Lipids 21, 702-709.

11 Berent, S.L., and Radin, N.S. (1981) Biochim. Biophys. Acta 664, 572-582.

12. Radin, N.S., and Berent, S.L. (1982) Methods Enzymol. 83, 596-603.

13. Redinbaugh, M.G., and Turley, R.B. (1986) Anal. Biochem. 153, $267-271$.

14. Tarr, G.E. (1986) in Methods of Protein Microcharacterization (Shively, J.E. eds) pp. 155-194, Humana Press, Clifton, NJ.

15. Perini, F., and Peters, B.P. (1982) Anal. Biochem. 123, 357-363. 
16. Hammond, K.S., and Papermaster, D.S. (1976) Anal. Biochem. 74, 292-297.

17. Tarentino, A.L., and Plummer, Jr., T.H. (1987) Meth. Enzymol.138, 770-778.

18. Heukeshoven, J., and Dernick, R. (1985) Electrophoresis 6, 103-112.

19. Kleinschmidt, T., Christomanou, H., and Braunitzer, G. (1987) Biol. Chem. Hoppe-Seyler 368, 1571-1578.

20. Tarentino, A.L., Gomez, C.M., and Plummer, Jr., T.H. (1985) Biochemistry 24, 4665-4671.

21. Takasaki, S., Murray, G.J., Furbish, F.S., Brady, R.O., Barranger, J.A., and Kobata, A. (1984) J. Biol. Chem. 259, 10112-10117.

22. Goldstone, A., and Koenig, H. (1974) Biochem. J. 141, 527-535.

23. Weber, K., Pringle, J.R., and Osborn, M. (1972) Meth. Enzymol. 26, 3-27.

24. Fujibayashi, S., and Wenger, D.A. (1986) J. Biol. Chem. 261, 15339-15343.

25. Chiao, Y., Chambers, J.P., Glew, R.H., Lee, R.E., and Wenger, D.A. (1978) Arch. Biochem. Biophys. 186, 42 51.

26. Datta, S.C., Snider, R.M., and Radin, N.S. (1986) Biochim. Biophys. Acta 877, 387-398.

27. Kornfeld, A., and Kornfeld, S. (1985) Ann. Rev. Biochem. 54, 631-664.

28. Radin, N.S. (1982) in Gaucher Disease: A Century of Delineation and Research (R.J. Desnick, S. Gatt, and G.A. Grabowski, eds.) pp. 357-383. Alan R. Liss, NY. 